\title{
Situações de estresse no vôlei de praia de alto rendimento: um estudo de caso com uma dupla olímpica
}

Joice Stefanello

\section{RESUMO}

O estresse competitivo é um dos factores psicológicos mais determinantes para o desempenho esportivo no alto rendimento, pois, neste contexto, os atletas são submetidos às mais diversas pressões competitivas. Este estudo, realizado com uma dupla masculina do vôlei de praia brasileiro, primeira colocada no ranking nacional/internacional da modalidade (2003), pretendeu analisar as situações geradoras de estresse aos atletas nas etapas do circuito mundial 2004 que antecederam sua participação nos Jogos Olímpicos de Atenas, como os atletas vivenciaram o estresse competitivo e que técnicas de controle do estresse utilizaram. Para a coleta de dados, usou-se um segmento específico do instrumento de feedback de execução (adaptado de Ravizza, 1991), onde os atletas registravam as situações estressantes de cada partida, o modo como vivenciavam o estresse e as técnicas de controle empregadas. Os resultados demonstraram que os fatores situacionais foram os mais determinantes e, dentre estes, os aspectos relacionados ao jogo foram os fatores específicos mais influentes, tendo na facilidade/dificuldade da partida a principal fonte de estresse para os atletas. Os pensamentos e as emoções/sensações corporais corresponderam ao principal modo como o estresse foi vivenciado; e as técnicas cognitivas (auto-informe, concentração, imaginação), as mais empregadas pelos atletas.

Palavras-chave: estresse competitivo, vôlei de praia, alto rendimento

\author{
Departamento de Educação Física \\ Universidade Federal do Paraná \\ Brasil
}

\author{
ABSTRACT \\ Situations of stress in high performance beach volley: \\ a case study with an olympic pair
}

Competitive stress is one of the most determining psychological factors to high performance sport, for, in that context, the athletes face all kinds of competitive pressure. This research, done with a brasilian beach volley Olympic pair, first on the national/international ranking (2003), intends to analyse the stress-generator situations for athletes in the 2004 World Tour, which preceded their participation on the Athens Olympic Games, how the athletes lived competitive stress and what stress-controlling techniques they used. The data were collected with a specific performance feedback instrument (adapted from Ravizza, 1991), in which the athletes registered their every-game stressing situations, how they lived them and the controlling techniques used. Results show that situational elements were the most determinating and, among them, the game-related aspects were the most influent specific factors, being the difficulty/easyness of the match the main source of stress for the athletes. Thoughts and body emotions/sensations correspond to the main way through which athletes face stress; the cognitive techniques (self-information, concentration, imagination), the most used by the athletes.

Key-words: competitive stress, beach volley, high performance 


\section{INTRODUÇÃO}

O estresse competitivo tem sido considerado um dos factores psicológicos mais determinantes para o desempenho esportivo, especialmente no alto rendimento. Nesse contexto, os atletas são, frequentemente, submetidos aos mais diversos tipos de pressão competitiva, tendo de superar limites de forma vigorosa e manter a efectividade e a regularidade do seu desempenho diante dos mais elevados níveis de exigências físicas, técnicas, tácticas e psicológicas $(8,32,36)$. Os diferentes tipos de pressão que o atleta sofre durante a competição podem gerar altos níveis de estresse, transformando-se em factores negativos e redutores do desempenho. Níveis elevados de estresse, em geral, aumentam a tensão muscular e criam déficits de atenção. Uma tensão muscular excessiva reduz a flexibilidade, a coordenação motora e a eficiência muscular, impedindo que os atletas adoptem rápidos comportamentos e padrões motores para evitar situações perigosas ou agir de maneira apropriada a um bom rendimento. Os déficits de atenção causam redução da capacidade de atenção, dúvidas acerca da capacidade pessoal, maior vulnerabilidade ou predisposição para a distracção e maior atenção a aspectos irrelevantes à tarefa $(5,17,19,25,34)$.

A competição esportiva, contudo, nem sempre representa uma fonte de estresse para o atleta. A experiência prática e a pesquisa empírica têm demonstrado que para alguns atletas a competição esportiva pode representar uma forte ameaça ao seu bem estar físico, psicológico e social e, para outros, pode ter um carácter desafiador e motivador. Compreende-se, assim, que o estresse pode ser gerado por situações directa ou indirectamente relacionadas a elas ou por situações inerentes ao processo competitivo, dependendo do próprio indivíduo e/ou do meio ambiente (10, 32, 33). Uma situação de estresse, portanto, só irá se manifestar quando houver um desequilíbrio entre a condição da acção individual e a condição situacional; isto é, quando ocorrer uma discrepância entre as capacidades da pessoa e as exigências da situação, ou entre as suas necessidades e as possibilidades de satisfazê-las, com importantes consequências para o indivíduo $(35,36)$.

As respostas dos atletas para os eventos competitivos parecem, pois, depender da avaliação da demanda e da qualidade de recursos que o indivíduo dispõe para lidar com cada situação. Assim, da mesma forma que situações já vivenciadas poderão influenciar as respostas dos atletas, novos conhecimentos e experiências poderão fazer com que o atleta desenvolva um sistema integrado de estruturas e conteúdos que irão interferir na sua análise. Por outro lado, as características e especificidades da modalidade esportiva também exercem um importante papel na compreensão do estresse competitivo, pois quando as características da modalidade são aliadas à pressão da competição, as situações geradoras de estresse para o atleta poderão assumir uma proporção ainda maior $(8,9,27)$.

Nessa perspectiva, a compreensão do estresse competitivo num contexto específico torna-se fundamental para que o atleta aprenda a manter o controle e o estado de fluidez e equilíbrio necessários para ser bem sucedido. O conhecimento das situações geradoras de estresse e do modo como os atletas vivenciam essas situações em diferentes contextos são partes importantes do processo de tomada de consciência, considerado um elemento crítico para que o atleta obtenha o necessário autocontrole para actuar num alto nível de rendimento(34). A tomada de consciência, além de permitir que o atleta reconheça seus pontos fortes e frágeis para potencializar suas capacidades e corrigir seus déficits, permite que o atleta se prepare mentalmente para a competição e desenvolva estratégias apropriadas para fazer frente àquelas situações que podem afectar negativamente a sua actuação esportiva.

Contudo, apesar de o vôlei de praia de alto rendimento ser um esporte extremamente dinâmico, no qual o atleta precisa desenvolver e colocar à prova um repertório de padrões e estratégias adequados aos mais elevados níveis de exigências competitivas, ainda há uma grande carência de investigações acerca das variáveis que predispõem atletas dessa modalidade a experimentarem uma maior ou menor percepção de ameaça na competição e, consequentemente, maior ou menor estresse, embora muitas investigações tenham examinado a natureza e a intensidade das respostas de estresse durante a competição em diferentes modalidades esportivas $(7,17,23,28,41)$. Assim, baseado no trabalho de suporte psicológico desenvolvido com uma dupla masculina de atletas profissionais do vôlei de praia brasileiro, este estudo 
procurou analisar as situações geradoras de estresse para os atletas nas etapas do circuito mundial que antecederam a sua participação nos Jogos Olímpicos de 2004, como os atletas vivenciaram o estresse competitivo nessas situações e quais as técnicas mais eficientes de controle do estresse utilizadas pela dupla para eliminar ou minimizar os efeitos das situações estressantes sobre seu rendimento esportivo.

\section{METODOLOGIA}

\section{Participantes do estudo}

Este estudo de caso descritivo foi realizado com uma dupla masculina de atletas profissionais do vôlei de praia, primeira colocada no ranking nacional (campeã do circuito brasileiro) e internacional (campeã do circuito mundial e campeã mundial) em 2003, tendo por base o trabalho de suporte psicológico desenvolvido, por cerca de dois anos, durante a sua preparação para as Olimpíadas de Atenas (2004). As idades dos atletas eram de 29 e 31 anos (Atletas A e $\mathrm{B}$, respectivamente) e ambos já haviam participado de olimpíadas anteriores: em 1996 (Atleta B) e 2000 (Atletas A e B). Importante ressaltar que não são conhecidos dados de atletas de alto rendimento nessa modalidade.

\section{Cuidados éticos}

Inicialmente, atletas e comissão técnica foram informados a respeito do trabalho a ser realizado (aprovado pelo Comitê de Ética em Pesquisa de uma Universidade Federal) e das formas de divulgação dos resultados. Foi assegurado aos atletas que poderiam afastar-se do estudo no momento em que desejassem, obtendo-se, assim, o consentimento, a adesão e o comprometimento do grupo para o trabalho pretendido.

\section{Coleta de dados}

É importante ressaltar que o período referente à colecta dos dados tratados especificamente neste estudo (Maio a Agosto) correspondeu, apenas, a uma das fases do programa de treinamento de competências psicológicas, contemplando seis etapas do circuito mundial que antecederam os Jogos Olímpicos de 2004 (etapas da China, Sérvia e Montenegro, Portugal, Suíça, Alemanha e Noruega), totalizando 26 jogos. Durante essa fase do treina- mento psicológico (fase de prática), os atletas deveriam reconhecer seus pontos fortes e frágeis frente às diversas situações de pressão competitiva, procurando integrar, em situações competitivas reais e de forma sistemática na sua actuação esportiva, as competências psicológicas treinadas na fase anterior (fase de aquisição de técnicas e estratégias psicológicas), a fim de potencializar suas capacidades (pontos fortes) e corrigir seus déficits (pontos fracos), de modo a obter o necessário autocontrole para actuar no seu mais alto nível de rendimento.

O treinamento psicológico envolveu várias competências psicológicas, porém apenas os aspectos relacionados ao estresse competitivo foram abordados no presente estudo. Dessa forma, um segmento específico do instrumento feedback de execução, adaptado de Ravizza(34), destinado à avaliação do estresse competitivo em situações competitivas reais, foi empregado. O instrumento feedback de execução (modelo completo em anexo) é uma técnica que auxilia o atleta a reconhecer as situações que tendem a afectar negativamente o seu rendimento, aumentando a sua conscientização acerca da sua própria actuação e permitindo-lhe desenvolver estratégias de confronto para enfrentá-las apropriadamente. No segmento específico do feedback de execução utilizado no presente estudo, os atletas deveriam registrar as situações geradoras de estresse em cada partida, o modo como vivenciavam o estresse (pensamentos, ações e/ou sensações) e as técnicas e/ou estratégias psicológicas utilizadas para manter ou recuperar o autocontrole diante dos diferentes agentes estressantes. O preenchimento da ficha era feito por escrito pelos próprios atletas 30 minutos após o encerramento de cada partida, para que pudessem reflectir sobre os acontecimentos do jogo e sobre a sua actuação.

\section{APRESENTAÇÃO E DISCUSSÃO DOS RESULTADOS}

De acordo com os objectivos propostos, serão apresentados, primeiramente, os resultados referentes às situações consideradas pelos atletas como geradoras de estresse; em seguida, os dados relativos ao modo como os atletas experimentaram as situações estressantes (pensamentos, acções e/ou sensações) e, por fim, as técnicas psicológicas utilizadas pelos atletas para eliminar ou minimizar os efeitos dos factores estressantes sobre seu rendimento esportivo. 
Os dados de cada atleta foram analisados, individualmente, de acordo com os procedimentos propostos por Giglione e Matalon(11) para a análise de conteúdo. Dessa forma, inicialmente, os indicadores referidos pelos atletas em cada jogo (situações geradoras de estresse, modo como o estresse foi experimentado e estratégias utilizadas) foram listados tal como expressos pelos atletas, sem excluir ou agrupar qualquer item. Em seguida, considerando os 26 jogos disputados pela dupla, juntaram-se num único indicador os itens referidos pelos atletas que apresentavam significados comuns (proposições idênticas ou com o mesmo complemento), obtendo-se, assim, o percentual com que cada indicador foi apontado pelos atletas nos 26 jogos analisados. Todos esses indicadores foram, posteriormente, analisados e discutidos conjuntamente com os atletas (uma vez que faziam parte do trabalho de suporte psicológico desenvolvido com a dupla), assegurando-se, assim, a sua confiabilidade.

\section{Situações causadoras de estresse}

Tomando por base o estudo desenvolvido por De Rose Junior, Deschamps e Korsakas com atletas profissionais de basquetebol( ${ }^{(8)}$, as situações consideradas pelos atletas do vôlei de praia como geradoras de estresse que apresentavam características similares foram agrupadas em fontes específicas de estresse (lesões, competência, conduta dos adversários, facilidade/dificuldade da partida, arbitragem, torcida, condições climáticas, equipe, organização dos jogos), que, por sua vez, foram classificadas em factores específicos de estresse (aspectos físicos, estados psicológicos, jogo, planejamento/organização), que, quando novamente agrupados em função da sua origem e/ou características, foram categorizados em factores gerais de estresse (individuais e situacionais).

Os Quadros 1 e 2 mostram as situações, as fontes e os factores (específicos e gerais) de estresse vivenciados pelos Atletas A e B, respectivamente.

Quadro 1. Situações, fontes e factores (específicos e gerais] de estresse vivenciados pelo Atleta $A$

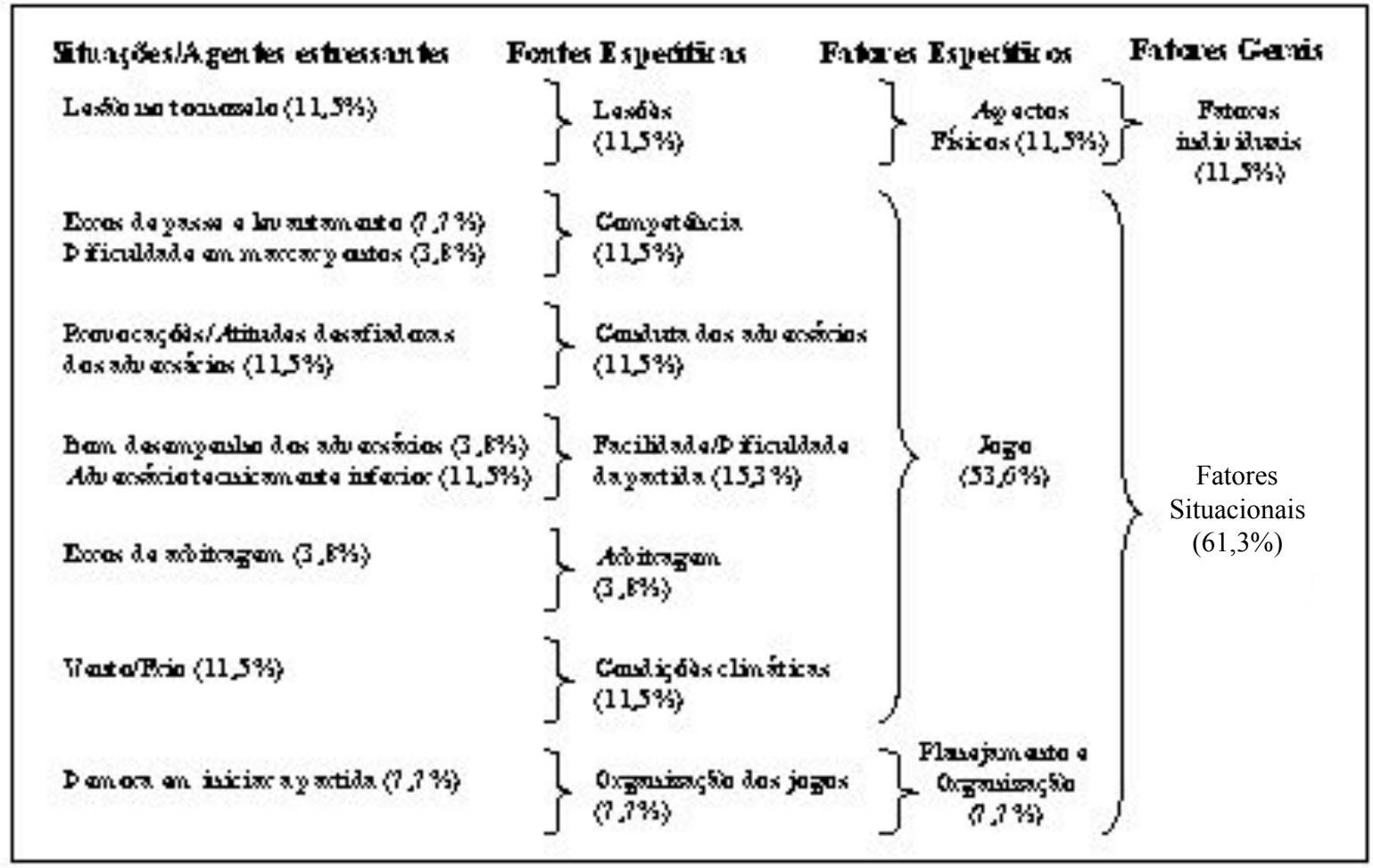

0 percentual apresentado entre parêntese no Quadro 1 corresponde ao número de jogos em que cada situação, fonte e factores (específicos e gerais] de estresse foram vivenciados pelo atleta $A$, considerando os 26 jogos disputados. 


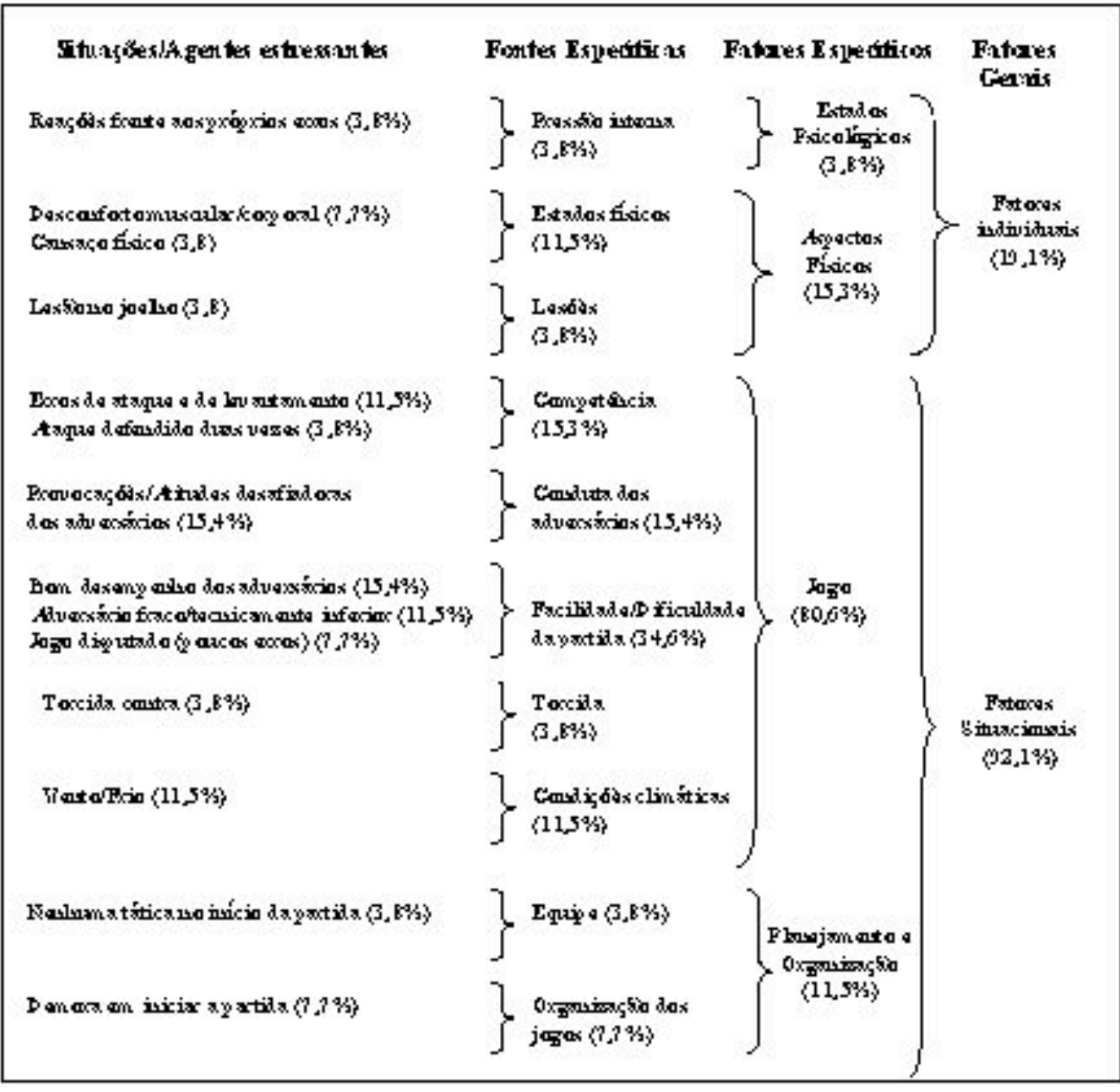

0 percentual apresentado entre parêntese no Quadro 2 corresponde ao número de jogos em que cada situação, fonte e factores (específicos e gerais] de estresse foram vivenciados pelo atleta $B$, considerando os 26 jogos disputados.

Conforme indicam os Quadros 1 e 2, os factores situacionais predominaram em relação aos individuais. Os factores situacionais, referindo-se aos aspectos objectivos do evento, estão relacionados com a natureza imediata da situação estressante e ocorrem a partir de situações que são comuns ao contexto competitivo. Os factores pessoais ou individuais, voltados às tentativas individuais de resolução de um problema, dependem quase exclusivamente do indivíduo(8). Apesar de representarem situações diferenciadas, vale ressaltar que ambos os factores estão intimamente relacionados, isto é, a avaliação 
situacional está relacionada com a selecção individual de respostas para um dado problema(24). Dessa forma, o presente estudo dá ênfase aos processos de avaliação cognitiva, que, de acordo com alguns estudiosos $(5,14,38)$, assumem o papel de mediador entre as circunstâncias ambientais enfrentadas, os objectivos e as crenças pessoais dos atletas e sua resposta emocional, sendo considerados o primeiro estágio no processo de resolução de um problema. De acordo com essa perspectiva teórica, o estresse competitivo depende da avaliação que o atleta faz das exigências, dos recursos que julga dispor para lidar com essas exigências, da avaliação das conseqüências se essas exigências não forem correspondidas e do significado que as possíveis consequências terão para ele ${ }^{(14)}$. Assim, tal como se poderá perceber nos dados analisados a seguir, a avaliação de uma circunstância como ameaçadora, parecem não depender apenas do perigo objectivo inerente a cada situação, mas também das características individuais da pessoa, das suas experiências passadas e da sua própria capacidade de controle.

\section{Fatores competitivos situacionais}

O jogo foi o principal factor específico situacional de estresse vivenciado pelos atletas, aparecendo em $53,6 \%$ das partidas disputadas pelo Atleta A e em $80,6 \%$ das partidas disputadas pelo Atleta B. Como fontes de estresse mais significativas relacionadas a esse factor, encontrou-se a facilidade/dificuldade da partida, a competência dos atletas e a conduta dos adversários. A facilidade/dificuldade da partida pareceu ser a fonte de estresse mais influente, sendo referida em $15,3 \%$ e $34,6 \%$ dos jogos, respectivamente, para os Atletas A e B e decorreram do bom desempenho dos adversários, por um lado, e da inferioridade técnica destes, por outro.

A facilidade/dificuldade da tarefa/jogo como fonte de estresse também foi encontrada num estudo conduzido com atletas adultos masculinos de basquetebol, todos com participação em Jogos Olímpicos e/ou Campeonatos Mundiais ${ }^{(8)}$. Para os autores desse estudo, a displicência gerada em jogos considerados mais fáceis, leva muitas vezes a um aumento dos níveis de estresse e a um mau desempenho, ocasionando, inclusive, derrotas inesperadas.
Contrariamente, tem-se constatado que quando o desafio é maior do que a percepção da capacidade do atleta em superá-lo, sua preocupação poderá conduzi-lo a um excesso de inquietude e ansiedade, impedindo-o de actuar no seu nível potencial(19), tal como pareceu ocorrer com os atletas do vôlei de praia diante da inferioridade técnica dos adversários. A competência, envolvendo capacidades e habilidades no desempenho de movimentos específicos, pareceu ser responsável pelo estresse competitivo do Atleta A em 11,5\% dos jogos, sendo decorrente dos erros de passe/levantamento e da dificuldade em marcar pontos. No caso do Atleta B (15,3\%), deu-se devido aos erros cometidos (ataque/levantamento) e à ineficácia do ataque (ataque defendido consecutivamente). Em jogadores olímpicos de basquetebol(8), a competência também demonstrou ser uma importante fonte de estresse. Os atletas desse estudo reconheceram que errar, repetir os mesmos erros ou não tentar, omitindo-se no jogo, são situações comuns de estresse durante as partidas. Também, num estudo sobre o estresse psíquico em atacantes de voleibol(32), não superar uma marcação específica de um jogador durante uma partida constituiu-se numa situação muito estressante para os atletas, assim como a falha do levantador, colocando o atacante em uma situação de pressão e cobrança.

A conduta dos adversários teve nas provocações/atitudes desafiadoras dos oponentes as situações de estresse mais significativas para ambos os atletas do vôlei de praia (em 11,5\% e 15,4\% dos jogos, respectivamente, para os Atletas A e B). Em atletas olímpicos de basquetebol( ${ }^{(8)}$, os adversários também tiveram sua parcela de contribuição para elevar os níveis de estresse dos atletas. Para os autores desse estudo, isso ocorre mais em função de comportamentos como provocar e usar de deslealdade para tentar parar um jogador, do que da capacidade técnica ou da ameaça que os adversários representam para a equipe. Estudos com jogadores de voleibol $(29,32)$ demonstraram que as intimidações ou provocações dos adversários partem de gestos, palavras e olhares, muitas vezes, sutis e imperceptíveis para a arbitragem e, em outras vezes, acontecem de forma mais acintosa e directa, podendo, inclusive, levar o atleta a uma atitude mais agressiva. Tem-se evidenciado, 
ainda, que o uso sistemático, intencional e planejado da guerra psicológica pelo adversário(5) visa a debilitar o rendimento do atleta, através do aumento da ansiedade e/ou nervosismo, da diminuição da autoconfiança e dos consequentes erros e dificuldades, pois quebra a atenção/concentração, perturba a preparação psicológica e mental do atleta, quebra o rendimento e provoca estados emocionais e psicológicos extremamente vulneráveis e pouco adequados às tomadas de decisão ou processamento da informação. As condições climáticas (vento/frio durante as partidas) também foram fontes de estresse para os atletas do vôlei de praia ( $11,5 \%$ dos jogos), assim como os erros de arbitragem (para o Atleta A) e a torcida contra (para o Atleta B), presentes em 3,8\% dos jogos. O planejamento/organização, por sua vez, representando o segundo factor competitivo situacional encontrado para os atletas dessa modalidade, teve como fonte de estresse mais significativa a organização dos jogos (7,7\%), especialmente, devido a demora em iniciar a partida.

Tanto as condições climáticas quanto o planejamento/organização dos jogos, parecem constituir-se em potenciais fontes de estresse para os atletas do vôlei de praia, por ocasionar alguma influência na actuação dos atletas e na sua preparação para a competição, impedindo-os de actuar no seu nível potencial. Alguns autores $(31,35,39,40)$ têm referido que variações climáticas, ruídos/estímulos visuais (movimentação e agitação da torcida), fadiga, pressão dos adversários e arbitragem constituem distracções características de determinadas modalidades, podendo influenciar nos níveis de activação e de ansiedade dos atletas. Em outros estudos, englobando situações relacionadas à estrutura administrativa das equipes ou entidades esportivas, o planejamento/organização dos jogos ${ }^{(8)}$ e as situações ou acontecimentos imprevistos $^{(5,21)}$ também representaram significativas situações de estresse para os atletas.

\section{Fatores competitivos individuais}

Nessa categoria, os aspectos físicos foram os factores específicos de estresse encontrados para ambos os atletas do vôlei de praia, assim como os estados psicológicos para o Atleta B. Quanto aos aspectos físicos, as lesões pareceram ser as principais fontes de estres- se para ambos os atletas ( $11,5 \%$ e $3,8 \%$ dos jogos, respectivamente para os Atletas A e B) e os estados físicos (para o Atleta $B$ em 11,5\% dos jogos), representados pelo desconforto muscular/corporal e cansaço físico. Por outro lado, a pressão interna (para o Atleta B, em 3,8\% dos jogos), teve nas reacções do próprio atleta frente aos erros cometidos a principal fonte específica de estresse.

Os aspectos físicos, também para atletas olímpicos de basquetebol(8), têm sido apontados como um importante factor individual de estresse, estando relacionados às condições físicas dos atletas (tal como jogar mal preparado) e às contusões.

Resultados semelhantes também foram encontrados em esportes como atletismo, patinação artística, futebol, handebol e natação $(1,14,21,22)$.

Os estados psicológicos, representados por fontes como medos/inseguranças, expectativas/objectivos e pressões internas, também corresponderam a factores específicos de estresse para atletas olímpicos de basquetebol(8). Nesse estudo, as pressões internas tiveram destaque e mostraram que a maioria dos atletas tinha muita responsabilidade, conhecendo seu papel como atleta de alto nível, apresentando um nível de autocobrança muito elevado e não aceitando o erro. Ainda, as expectativas dos níveis de rendimento esperados e exigidos (preocupação com o fato de ter que render em nível de suas capacidades; preocupação com companheiros e/ou expectativas dos outros; dúvidas pessoais quanto à actuação física, técnica e/ou psicológica; medo ou receio de falhar numa situação importante e/ou de ter um rendimento inadequado; medo ou receio de lesões) também foram apontados por diferentes estudio$\operatorname{sos}(5,13,18)$ como principais factores geradores de estresse no esporte de alto rendimento.

Esses dados parecem reforçar a ideia de que o grau de ameaça percebido (do qual se originam os sentimentos de preocupação e ansiedade, característicos de uma situação de estresse) depende da avaliação que o atleta faz do contexto global da situação, ou seja, da comparação que ele estabelece entre as exigências da situação e a relevância, a congruência motivacional, as opções, os recursos pessoais e as perspectivas de confronto que o atleta julga dispor para conseguir o êxito desejado(5). 


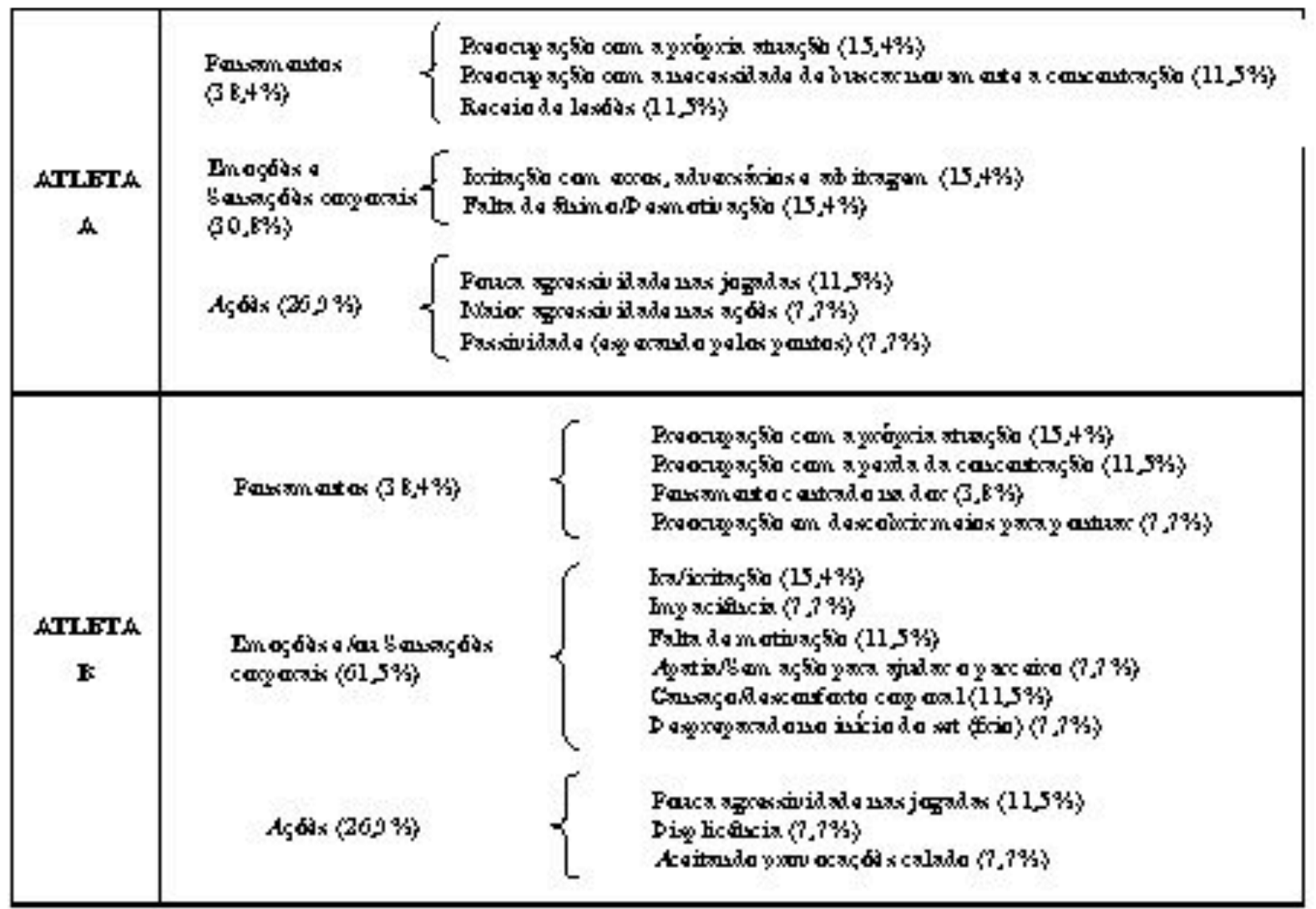

\section{Modo como os atletas vivenciaram o estresse}

No presente estudo, o modo como os atletas vivenciaram o estresse competitivo corresponde às consequências por eles percebidas como decorrentes das situações geradoras de estresse. Dessa maneira, as respostas dos atletas do vôlei de praia às situações geradoras de estresse foram agrupadas, tal como sugere Ravizza(34), em três categorias gerais: pensamentos, emoções/sensações corporais e acções (Quadro 3).

Os pensamentos pareceram representar o principal modo pelo qual o Atleta A vivenciou o estresse competitivo (38,4\% dos jogos), enquanto as emoções/sensações corporais foram a forma como o estresse pareceu se manifestar no caso do Atleta B $(61,5 \%)$. Os pensamentos voltados para a preocupação com a própria actuação $(15,4 \%)$ e com a necessidade de buscar novamente a concentração $(11,5 \%)$ foram comuns a ambos os atletas. Por outro lado, enquanto o pensamento do Atleta A esteve voltado para o receio de lesões $(11,5 \%)$, os pensamentos do Atleta $B$ estiveram centrados na necessidade de buscar novos meios para pontuar $(7,7 \%)$ e na dor originada pela contusão $(3,8 \%)$. As emoções e/ou sensações corporais pareceram estar, no caso do Atleta A, relacionadas à irritação com erros, adversários e arbitragem $(15,4 \%)$ e à falta de ânimo/motivação diante da inferioridade dos adversários $(15,4 \%)$. Para o Atleta $\mathrm{B}$, o estresse competitivo pareceu manifestar-se por meio da ira/irritação diante das provocações ou atitudes desafiadoras dos adversários $(15,4 \%)$, da impaciência diante dos erros cometidos $(7,7 \%)$, da falta de motivação $(11,5 \%)$ e apatia $(7,7 \%)$ diante dos adversários mais fracos, do cansaço/desconforto corporal $(11,5 \%)$ e do despreparo no início do set $(7,7 \%)$. No que diz respeito às acções, o estresse competitivo 
vivenciado pelo Atleta A manifestou-se na pouca agressividade de algumas jogadas $(11,7 \%)$, na sua passividade em outras $(7,7 \%)$ e numa maior agressividade em $7,7 \%$ das suas ações. No caso do Atleta $\mathrm{B}$, o estresse competitivo tornou-o pouco agressivo em $11,5 \%$ dos jogos, displicente em 7,7\% das partidas e calado diante das provocações dos adversários em $7,7 \%$ dos jogos disputados.

Alguns estudos também têm demonstrado que o estresse competitivo pode apresentar sintomas negativos na área mental, física e comportamental, manifestando-se por meio da preocupação, medo, ansiedade, dificuldade de concentração( ${ }^{(3,31)}$, confusão, esquecimento de detalhes, volta a antigos hábitos e incapaci- dade para tomar decisões ${ }^{(5,19)}$, oscilação nos níveis de activação(15, 37), sensação de fadiga, sensação de frio, aceleração do ritmo cardíaco, aumento da tensão arterial, respiração mais rápida $(5,19)$, perda da motivação, agressividade, nervosismo, irritabilidade (15), falta de confiança e performances fracas $(12,30,35)$.

O que se percebe, é que pensamentos pouco apropriados ou erróneos, geralmente, conduzem a sentimentos negativos e a uma execução pobre e que os pensamentos que se centram na pessoa, especificamente, são os que causam maiores problemas aos atletas(20). Quando os indivíduos se orientam no sentido interno, preocupando-se demasiadamente com o seu próprio bem-estar e sentimentos, a sua

Quadro 4. Técnicas utilizadas pelos atletas para o controle do estresse.

\begin{tabular}{|c|c|c|}
\hline $\begin{array}{c}\text { ATLETA } \\
A\end{array}$ & 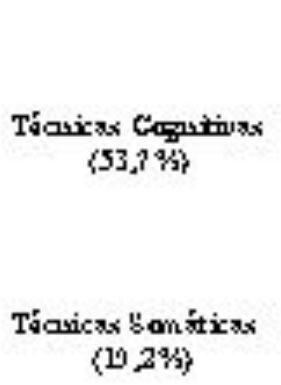 & 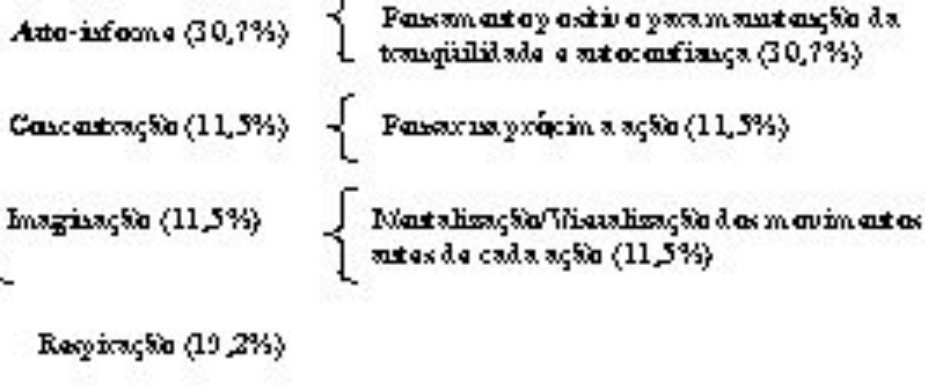 \\
\hline$\underset{B}{A T E T A}$ & 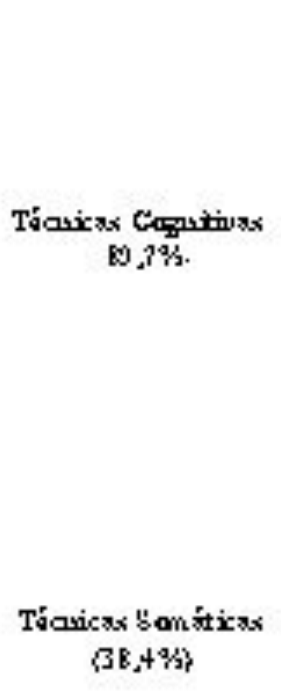 & 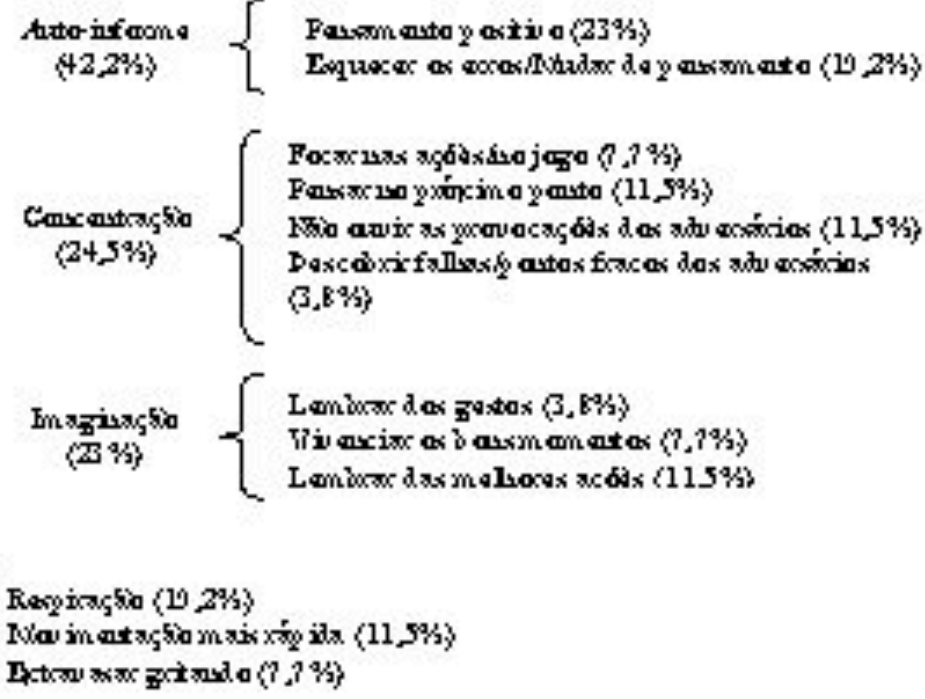 \\
\hline
\end{tabular}


preocupação poderá conduzir a reacções físicas e mentais aumentadas, interferindo consideravelmente na actuação dos atletas: a sua capacidade de prever e interpretar estímulos externos e informações relevantes reduz-se; a sua inquietude acerca de uma actuação iminente gera ansiedade (somática e/ou cognitiva); a sua tolerância diante da frustração e da dor diminui (tendendo à irritação e à queixa); e os seus erros são maximizados e interpretados como mais desastrosos do que na realidade o são(19, 20). A oscilação nos níveis de activação dos atletas durante uma partida, por sua vez, tem sido referido(37) como um factor que pode levar um atleta destacado a performances fracas. Alguns estudiosos ${ }^{(2,19,}$ 31) têm constatado que as motivações para a competição e as sensações positivas que acompanham as realizações esportivas podem levar a um aumento da activação positiva, promovendo um estado ideal de execução, enquanto que a ansiedade, o aborrecimento, a raiva e o medo do fracasso parecem repercutir num aumento da activação negativa, deteriorando o desempenho do atleta. Além disso, estados emocionais, como euforia, raiva, irritabilidade, entre outros, especialmente quando intensos e persistentes, parecem consumir rapidamente a energia do atleta, contribuindo para o surgimento de um estado de fadiga (cansaço físico ou emocional) ${ }^{(12,30)}$.

Diante desses achados, parece ser plausível que o estresse competitivo não depende apenas do perigo objectivo inerente à situação, mas também do modo como o atleta o percebe e a ele reage.

\section{Técnicas para o controle do estresse}

As técnicas para o controle do estresse correspondem às estratégias de intervenção utilizadas conscientemente pelos atletas diante das situações geradoras de estresse e das suas consequências sobre a actuação do esportista. Essas técnicas objectivam auxiliar o atleta a obter o necessário autocontrole para actuar no seu mais alto nível de rendimento esportivo, evitando interferências provenientes de distracções internas e externas sobre o seu desempenho. No presente estudo, as técnicas ou estratégias referidas pelos atletas do vôlei de praia para manter e/ou recuperar o seu autocontrole foram agrupadas em técnicas cognitivas e somáticas.
As técnicas cognitivas, as mais utilizadas por ambos os atletas, baseiam sua acção na modificação ou no ajuste dos principais determinantes do comportamento (pensamento, percepção, memória, afecto, linguagem). Essas técnicas ressaltam que, para ocorrer uma melhora na conduta ou nos estados emocionais, o sujeito deve promover uma mudança nos pensamentos subjacentes a esses comportamentos $(5$, 35). Essa ideia reforça o entendimento de que os processos de avaliação cognitiva cumprem um importante papel como mediadores do estresse e da ansiedade no contexto esportivo, auxiliando os atletas a manter o autocontrole e o equilíbrio necessários a uma boa actuação.

Dentre as técnicas cognitivas referidas pelos atletas do vôlei de praia, o auto-informe ou monólogo interno foi a mais utilizada. O Atleta A valeu-se do autoinforme em 30,7\% dos jogos, recorrendo à estratégia de pensamento positivo para a manutenção da tranquilidade e autoconfiança. O Atleta B utilizou-se do auto-informe em $42,2 \%$ dos jogos, recorrendo ao pensamento positivo (23\%) e a mudança de pensamento para esquecer os erros cometidos $(19,2 \%)$. $\mathrm{O}$ auto-informe, conversa interna do praticante com ele mesmo(2), objectiva bloquear ou modificar pensamentos e estados emocionais negativos, compreendendo desde experiências silenciosas até vocalizações em voz baixa. Alguns estudiosos $(4,20,30)$ também têm apontado que o auto-informe pode ser utilizado para a reprogramação de técnicas/estratégias a fim de evitar a repetição de erros, para manter a mente focalizada, para o controle do esforço e manutenção do estado de ânimo e para a promoção/manutenção da autoconfiança e expectativa de êxito. Dentre as estratégias mais referidas na literatura $(4,20,34)$ para manutenção do autocontrole estão também a interrupção de pensamentos negativos ou contraproducentes, a manutenção de pensamentos positivos e a mudança de pensamento. Os atletas do vôlei de praia fizeram, ainda, uso das técnicas cognitivas de concentração e de imaginação. O Atleta A recorreu à técnica de concentração em $11,5 \%$ dos jogos, voltando seu pensamento para a próxima acção. O Atleta B utilizou-se da técnica de concentração em $24,5 \%$ dos jogos, procurando focar sua atenção nas próprias acções/jogo (7,7\%), pensar no próximo ponto $(11,5 \%)$, não ouvir as provoca- 
ções dos adversários $(11,5 \%)$ e descobrir as falhas ou os pontos fracos dos adversários $(3,8 \%)$.

As técnicas de concentração objectivam ajudar o atleta a desenvolver a conscientização sobre factores que desviam sua atenção e por que o fazem, permitindo-lhe modificar aspectos do seu rendimento e/ou trabalho que são ineficientes e distanciar-se de padrões de comportamento e pensamentos negativos ou não produtivos(31). Usar palavras-chave para focalizar a atenção, concentrar-se na situação presente, na tarefa a realizar, nos momentos decisivos da actuação esportiva e na próxima acção também foram algumas das estratégias referidas na literatura científica $(31,35,40)$ para auxiliar os atletas diante dos agentes estressantes.

A técnica de imaginação foi utilizada pelo Atleta A em 11,5\% dos jogos, por meio da mentalização/visualização dos movimentos antes de cada acção. O Atleta B usou a imaginação em 23\% dos jogos para lembrar dos gestos $(3,8 \%)$ e das melhores acções $(11,5 \%)$ e vivenciar os bons momentos $(7,7 \%)$.

A técnica da imaginação consiste na repetição planejada da imaginação consciente de uma acção esportiva, sendo apontada $(6,20,35,39,40)$ como uma importante ferramenta psicológica para melhorar o rendimento dos atletas e utilizada com sucesso para a manutenção de competências motoras, para a regulação da activação, para o controle de respostas emocionais e para a promoção da autoconfiança.

As técnicas somáticas, embora num menor percentual, também foram empregadas pelos atletas do vôlei de praia (Atleta A em 19,2\% dos jogos e Atleta B, em $38,4 \%$ dos jogos). A técnica somática mais utilizada pelos atletas foi a respiração, em $19,2 \%$ dos jogos (diminuição da frequência respiratória, com uma expiração mais forte). O Atleta B fez uso também do movimento para melhorar o seu nível de activação, movimentando-se mais rapidamente em $11,5 \%$ dos jogos e procurou extravasar a tensão e a raiva vivenciadas durante alguns jogos, gritando $(7,7 \%)$.

As técnicas somáticas são intervenções voltadas para o ajuste de reacções corporais como tensão muscular, frequência cardíaca e frequência respiratória, a fim de oportunizar maior controle sobre o estresse, a ansiedade e o aperfeiçoamento motor(2).

Alguns estudos $(2,19,35)$ também têm evidenciado que o aumento da frequência respiratória (com uma ins- piração mais forte) é bastante eficiente diante de situações que requerem aumento nos níveis de activação do atleta, assim como a diminuição da frequência respiratória (com uma expiração mais forte) tem conseguido reduzir os níveis de activação dos atletas, propiciando o relaxamento e a diminuição da tensão gerada pela pressão competitiva. Por outro lado, o aumento da intensidade do movimento (movimentação mais rápida) tem sido eficaz para aumentar os níveis de activação dos atletas, na intenção de auxiliálos a actuar mais proximamente ao seu estado ideal de execução em diferentes momentos da competição, assim como a diminuição da intensidade do movimento (movimentação mais lenta) tem contribuído para reduzir os seus níveis de activação, quando estes demonstram ser excessivos ${ }^{(2)}$.

\section{CONCLUSÃO}

No presente estudo, para ambos os atletas, as situações geradoras de estresse relacionadas aos factores situacionais predominaram em relação aos fatores individuais. Dentre os factores competitivos situacionais, o factor jogo foi o principal factor específico de estresse vivenciado pelos atletas, tendo na facilidade/dificuldade da partida a fonte de estresse mais influente, devido, especialmente, ao bom desempenho dos adversários e à inferioridade técnica destes. A competência, a conduta dos adversários e as condições climáticas foram as demais fontes de estresse relacionadas ao factor jogo que se mostraram significativas aos atletas. A competência esteve associada, principalmente, aos erros cometidos; a conduta dos adversários, às provocações/atitudes desafiadoras destes; e, as condições climáticas, ao vento/frio durante as partidas. Por outro lado, os factores competitivos individuais mais influentes para os atletas foram os aspectos físicos. Destes, o medo/receio de lesões foi a fonte de estresse mais evidente para o Atleta A, enquanto os estados físicos, como desconforto muscular/corporal e cansaço físico, foram os mais significativos para o Atleta B.

O modo como os atletas vivenciaram o estresse competitivo manifestou-se nos seus pensamentos, nas suas emoções e/ou sensações corporais e nas suas ações durante a partida. Os pensamentos decorrentes das situações de estresse, comuns a ambos os atletas, centraram-se na preocupação com a própria 
actuação e perda da concentração. As emoções e/ou sensações corporais originadas a partir do estresse percebido foram a ira ou irritação com os próprios erros, com os erros da arbitragem e com as provocações/atitudes desafiadoras dos adversários, além da falta de ânimo ou motivação diante dos oponentes mais fracos. No que diz respeito às acções, as respostas às situações de estresse mais evidentes para ambos os atletas foram a pouca agressividade nas jogadas e a passividade ou displicência dos atletas nas acções.

Para o controle do estresse, os atletas recorreram, predominantemente, às técnicas cognitivas, fazendo uso, especialmente, do auto-informe para a manutenção do pensamento positivo ou mudança do pensamento. As técnicas de concentração (focalização da atenção nas próximas acções ou no próximo ponto) e de imaginação (visualização dos movimentos antes de cada acção e lembrança das melhores acções) também foram utilizadas pelos atletas. Em muitos casos, ambos os atletas recorreram, ainda, ao uso de técnicas somáticas, sendo a respiração a mais empregada. Tal como se pode constatar no presente estudo, muitos factores, internos (pessoais ou individuais) e externos (situacionais), foram responsáveis pelo estresse competitivo no vôlei de praia de alto rendimento, sendo de fundamental importância que o atleta aprenda a lidar eficazmente com esses factores, a fim de conseguir recuperar e/ou manter o necessário autocontrole para actuar no seu mais alto nível de rendimento esportivo. De tal modo, como no esporte de alto rendimento sempre existirão formas reais de pressão, mais importante do que eliminar totalmente o estresse competitivo (o que é praticamente improvável), a preparação psicológica dos atletas deve procurar auxiliar o esportista a adquirir conhecimentos e estratégias mentais e físicas que lhe permitam responder de forma adaptativa às diversas situações de pressão que são inerentes ao processo competitivo. O reconhecimento das situações geradoras de estresse que podem afectar negativamente a sua actuação esportiva e dos efeitos que essas situações exercem na sua conduta, poderá ajudar o atleta a desenvolver a conscientização necessária acerca do seu próprio padrão de comportamento, permitindo-lhe usar estratégias de confronto apropriadas para enfrentá-las.
A utilização de técnicas cognitivas e somáticas, ora de forma isolada, ora conjuntamente, buscou atender as necessidades pessoais dos atletas, da equipe ou situacionais, compreendendo uma interessante possibilidade de abordagem para o estresse competitivo no vôlei de praia de alto rendimento. Contudo, vale ressaltar que o seu uso requer cautela, pois as técnicas e estratégias psicológicas antes de serem aplicadas em situações competitivas reais, necessitam ser bem aprendidas e treinadas adequadamente, considerando a que se propõem e para quais situações e indivíduos adaptam-se melhor.

Espera-se, por fim, que os resultados do presente estudo sejam de grande valia para todos os profissionais envolvidos na prática esportiva (treinadores, atletas, preparadores físicos etc.). Contudo, para ampliar a compreensão do estresse competitivo, recomenda-se, que estudos com outros atletas, outras modalidades esportivas e níveis competitivos sejam também realizados.

\section{CORRESPONDÊNCIA}

Joice Mara Facco Stefanello

Rua Alferes Ângelo Sampaio, 2125 - Apt $^{\circ} 703$

Bigorrilho - Curitiba - Paraná

Cep: 80730-460 Brasil

e-mail: joicestefanello@ig.com.br 


\section{REFERÊNCIAS}

1. Barbosa, LG, Cruz, JF (1997). Estudo do stress, da ansiedade e das estratégias de confronto psicológico no andebol de alta competição. Psicologia: teoria e investigação prática 2: 523-48.

2. Becker Júnior, B, Samulski, D (2002). Manual de treinamento psicológico para o esporte. 2.ed. Erechin, Fevale.

3. Brandão, M, Casal, H, Mendoza, M (2002). Estrés en jugadores de fútbol: una comparación Brasil \& Cuba. Cuadernos de Psicologia del Deporte 2(1): 7-14.

4. Bunker, L, Williams, JM (1991). Tecnicas cognitivas para la mejora de la ejecucion y la constuccion de la confianza. In: Williams, JM. Psicologia aplicada al deporte. Madrid, Biblioteca Nueva, p. 343-71.

5. Cruz, JF (1996). Stress, ansiedade e rendimento na competição desportiva. Braga: Lusografe.

6. Cruz, JF, Gomes, RA, Viana, MF, Almeida, P (1996). A intervenção do psicólogo no desporto: crenças e expectativas, problemas éticos e desafios futuros. In: Cruz, JF (ed.). Manual de psicologia do desporto. Braga: Lusografe, p. 129-43.

7. Cruz, JFA (1997). Stress, ansiedade e competências psicológicas em atletas de elite e de alta competição: relação com o sucesso desportivo. In: Cruz, JFA, Gomes, AR (eds.). Psicologia aplicada ao desporto e à actividade física. Braga: Universidade do Minho.

8. De Rose Junior, D, Deschamps, S, Korsakas, P (1999). Situações causadoras de "stress" no basquetebol de alto rendimento: fatores competitivos. Revista Paulista de Educação Física 13(2): 217-29.

9. De Rose Junior, D, Vasconcellos, EG, Simões, AC (1994). Situações de jogo causadoras de "stress" no handebol de alto nível. Revista Paulista de Educação Física 8(1): 30-7.

10. De Rose Junior, D, Vasconcellos, EG, Simões, AC, Medalha, J (1996). Padrão de comportamento do "stress" em atletas de alto nível. Revista Paulista de Educação Física 10(2): 139-45.

11. Ghiglione, R, Matalon, B (1993). O inquérito: teoria e prática. Oeiras: Celta Editora.

12. Goldstein, A (1999). Aggression reduction strategies: effective and ineffective. School Psychology Quaterly 14(1): 40-58.

13. González, JL (1997). Psicología del deporte. Madrid, Biblioteca Nueva.

14. Gould, D, Jackson, SA, Finch, L (1993). Sources of stress in national champion figure skaters. Journal of Sport and Exercise Psychology 15(2):134-59.

15. Greco, P, Benda, R (1998). Iniciação esportiva universal: da aprendizagem motora ao treinamento técnico. Belo Horizonte: Editora UFMG.

16. Hall, HK, Kerr, AW, Matthews, J (1998). Precompetitive anxiety in sport: the contribution of achievement goals and perfectionism. Journal of Sport and Exercise Psychology 20: 194-217.

17. Hanton, S, Thomas, O, Maynard, I (2004). Competitive anxiety responses in the week leading up to competition: the role of intensity, direction and frequency dimensions. Psychology of Sport and Exercise 5: 169-181.

18. Hardy, L., Mullen, R., \& Jones, G. (1996). Knowledge and conscious control of motor actions under stress. British Journal of Psychology 87: 621-636.

19. Harris, DV (1991). Tecnicas de relajacion y energetizacion para la regulacion del arousal. In: Williams, JM. Psicologia aplicada al deporte. Madrid: Biblioteca Nueva, p.277-306.

20. Harris, DV, Harris, BL (1987). Psicologia del deporte: integracion mente-cuerpo. Barcelona: Editorial Hispano Europea, S.A.

21. James, B, Collins, D (1997). Self-presentational sources of competitive stress during performance. Journal of Sport and Exercise Psychology 19: 17-35.

22. Jones, JG, Hardy, L (1990). Stress and performance in sport. Chichester: J. Willey \& Sons.

23. Jones, G, Swain, ABJ, Cale, A (1991). Gender differences in pre-competition temporal patterning and antecedents of anxiety and self confidence. Journal of Sport and Exercise Psychology (13): p.1-15.

24. Kaissidis-Rodafinos, A, Anshel, MH, Porter, A (1997). Personal and situational factors that predict coping strategies for acute stress among basketball referees. Journal of Sports Sciences, London 15: 427-36.

25. Landers, DM, Boutcher, SH (1991). Relação entre el arousal y la ejecución. In: Williams, JM. Psicologia aplicada al deporte. Madrid: Biblioteca Nueva, p.249-75.

26. Madden, CC, Kirby, RJ (1995). Gender differences in competitive stress. Perceptual and Motor Skills 80: 848-59.

27. Madden, CC, Summers, JJ, Brown, DF (1990). The influence of perceived stress on coping with competitive basketball. Intemational Journal of Sport Psychology 21: 21-35.

28. Martens, R, Burton, D, Vealey, RS, Bump, LA, Smith, DE (1990). Development and validation of the competitive state anxiety inventory-2 (CSAI-2). In: Martens, R, Vealey, RS, Burton, D (eds.), Competitive anxiety in sport. Champaign, IL: Human Kinetics.

29. Moreno, JH (1994). Fundamentos del deporte: análisis de las estructuras del juego deportivo. Barcelona: INDE Publicaciones.

30. Muñoz, A (2002). Conducta agressiva y deporte. Cuadernos de Psicologia del Deporte 2(1): 39-56.

31. Nideffer, RM (1991). Entrenamiento para el control de la atencion y la concentración. In: Williams, JM. Psicologia aplicada al deporte. Madrid, Biblioteca Nueva, p. 373-91.

32. Noce, F, Samulski, DM (2002). Análise do estresse psíquico em atacantes no voleibol de alto nível. Revista Paulista de Educação Física 16(2): 113-29.

33. Passer, MW (1984). Competitive trait anxiety in children and adolescents. In: Silva, JM, Weinberg, RS (eds). Psychological foundations of sport. Champaign, Human Kinetics, p.130-44.

34. Ravizza, K (1991). Incremento de la toma de conciencia para el rendimiento en el deporte. In: Williams, JM. Psicologia aplicada al deporte. Madrid: Biblioteca Nueva, p. 321-44.

35. Samulski, DM (2002). Psicologia do esporte: um manual para educação física, psicologia e fisioterapia. São Paulo: Manole.

36. Samulski DM, Chagas MH, Nitsch JR (1996). Stress: Teorias Básicas. Belo Horizonte: Editora Gráfica Costa \& Cupertino Ltda.

37. Schmidt, R (1993). Aprendizagem e performance motora. São Paulo: Movimento.

38. Terry, DJ (1991). Coping resources and situational appraisals as predictors of coping behaviour. Personality and Individual Differences, Oxford 12: 1031-47.

39. Vealey, R (1986). Conception of sport-confidence and competitive orientation: preliminary investigation and instrument development. Joumal of Sport Ppsychology (8): 221-46.

40. Weinberg, RS, Gould, D (1996). Fundamentos de psicologia del deporte y el ejercicio físico. Barcelona: Editorial Ariel, S.A.

41. Woodman, T, Hardy, L (2001). Stress and anxiety. In Singer, R, Hausenblas, HA, Janelle, CM (Eds.). Handbook of research on sport psychology. New York: Wiley, p. 290-318. 